\title{
Pneumothorax in Neonate
}

\author{
M Hassan ${ }^{1}$, M Begum ${ }^{2}$, S M Z Haque ${ }^{3}$, N Jahan ${ }^{4}$, A Mannan ${ }^{5}$, A W S Rob ${ }^{6}$
}

1 Dr. Mahmuda Hassan

Associate Professor

Dept. of Paediatrics

Ad-din Medical College, Dhaka

${ }^{2}$ Dr. Marium Begum

${ }^{3}$ Dr. S M Z Haque

Professor \& Director, NICU

Ad-din Medical College, Dhaka

${ }^{4}$ Dr. N Jahan

${ }^{5}$ Dr. A Mannan

${ }^{6}$ Dr. A W S Rob

$2,4,5,6$

Assistant Professor

Dept. of Paediatrics

Ad-din Medical College, Dhaka

\section{Correspondence}

Dr. Mahmuda Hassan

Associate Professor

Dept. of Paediatrics

Ad-din Medical College, Dhaka

e-mail : mahmudahasn@yahoo.com

\section{Introduction}

Pneumothorax is air between the visceral and the parietal pleura. It is one of the air leak syndrome which is more common in the newborn period.

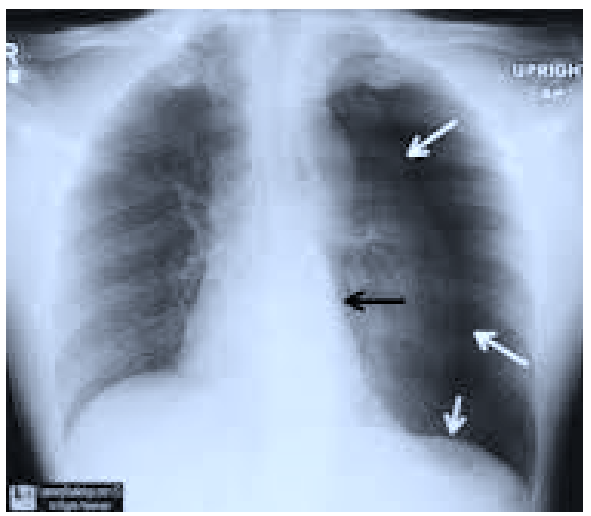

It can be spontaneous and secondary from underlying lung pathology or assisted ventilation. The causes of symptomatic spontaneous pneumothorax in term newborns are not completely understood. But the incidence is highest during neonatal period ${ }^{1}$ which is $0.05 \%-1 \%$ of all term newborns. This is most probably due to high negative transpulmonary pressure generated with the onset of breathing, may reach $100 \mathrm{~cm}$ of water to open the lungs that were collapsed in utero ${ }^{2}$. After the first few breath, this pressure is normalized and lungs takeover the function. If this transpulmonary pressure remains higher for a long period of time, it leads to alveolar rupture and consecutive pneumothorax. Secondery pneumothorax may be associated with respiratory distress syndrome(RDS), meconium aspiration syndrome(MAS), perinatal asphyxia (PNA), transient tachypnea of newborn (TTN), Sepsis, congenital pneumonia, congenital heart disease (CHD), pulmonary hypoplassia, diaphragmatic hernia. Also associated respiratory support with ventilator, nasal continuous positive airway pressure (NCPAP) seen. ${ }^{3}$ The early diagnosis and treatment of neonatal pneumothorax is crucial, to avoid complications like hypoxaemia, hypercarbia, or impaired venous return. ${ }^{4-6}$
Pulmonary air leak refers to accumulation of air outside the pulmonary space. Pulmonary interstitial emphysema(PIH) and pneumothorax are most common followed by pneumo-mediastinum and pneumo-pericurdium, pneumoperitonium.

\section{Clinical features of neonatal pneumothorax}

Pneumothorax occurs when air leaks between the visceral and parietal pleural surface. Pneumothorax can occur spontaneously in non-ventilated neonates or with assisted ventilation and aggressive cardio pulmonary resuscitation (CPR).

Spontaneous pneumothorax usually occurs during the first few breaths soon after birth. In this group, babies are usually asymptamatic. Only $0.05 \%$ to $1 \%$ are symptomatic and noted in full term and post mature babies.

Clinical picture starts in labour room or immediately after birth (during observations) as tahypnoea $(R R=>100)$, decreased air entry on affected side, bulged chest wall, grunting, retractions, cyanosis in room air. If air collection increases cyanosis is more evident even with oxygen. High index of suspicion is needed to diagnose a case of pneumothorax. Transillumination (whilst awaiting the X-ray) with a fiber optic light source placed chest wall illuminate the affected hemi-thorax. X-ray is the gold standard for diagnosing the pneumothorax.

Tension pneumothorax is common in ventilated babies; produces abrupt cyanosis, decreased heart rate, decreased $\mathrm{BP}$, metabolic acidosis, shifting of mediastinum to the opposite side. When baby is on ventilator pneumothorax is predicted in presence of increased ventilator pressure, low birth weight (LBW), severe RDS, (after surfactant therapy). Presence of trained nursing staff and doctors are essential to prevent and tackle the problem.

In some studies Pneumothorax followed by some amount of PIE or Pneumo mediastinum is very evident. $7,8,9$

\section{Management of pneumothorax}

\section{a) General Management}

Observation should be the treatment of choice for primary spontaneous small closed pneumothorax without significant breathlessness, in a spontaneously 
breathing patient. Inhalation of high concentrations of oxygen may speed the resolution of a pneumothorax by reducing the partial pressure of nitrogen in the pulmonary capillaries. This should increase the pressure gradient between the pleural cavity and pleural capillaries, so increasing the absorption of air from the pleural cavity. The rate of re-absorption of spontaneous pneumothoraces is $1.25-1.8 \%$ of the volume of hemithorax every 24 hour. ${ }^{10}$

\section{b) Procedure for the emergency management \\ i) Emergency needling}

Equipment and the procedure for the emergency needling (Aspiration) of pneumothorax

(a) Transilluminate the chest wall with Cold light for immediate detection of pneumothorax and when there is delay of portable X-ray for any reason. (b) $21 \mathrm{G}$ butterfly needle. (c) 3 way tap. (d) $10 \mathrm{cc}$ syringe. (e) $70 \%$ isopropile alcohol swab. (f) 1 pair sterile gloves

This procedure is very much effective in emergency situation and as well as life saving before doing the chest tube drainage. Sometime needling is enough to drain the air of pneumothorax and subsequently does not require for the chest tube drainage.

\section{Procedure}

- Infant supine, prepare area with alcohol wipe

- Insert needle into the pleural space (directly over the top of the rib in the $2^{\text {nd }}$ or $3^{\text {rd }}$ intercostal space in the mid-clavicular line) until air is aspirated into the syringe, then expel air through the 3-way stopcock.

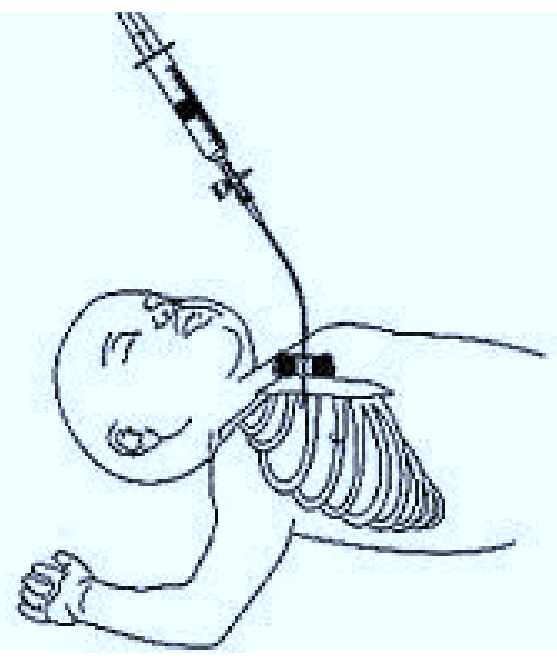

Simple aspiration is recommended as first-line treatment for all primary pneumothoraces requiring intervention but is less likely to succeed in secondary pneumothoraces. In the latter situation, it is only recommended as an initial treatment in small $(<2 \mathrm{~cm})$ pneumothoraces in minimally breathless patients. ${ }^{11-14}$

\section{ii) Chest tube drainage}

Equipment and the procedure for chest tube drainage of pneumothorax

(a) Sterile gloves. (b) 3-0 silk suture. (c) Curved artery forceps. (d) Scalpel blade No. 15 / No. 11. (e) Scissors. (f)Iodine solution. (g) Chest tube 8/10 Fr. (less than $2 \mathrm{Kg}$ ) $12 \mathrm{Fr}$. (more than $2 \mathrm{Kg}$ ). (h) Sterile dress. (i) Suction drainage system/ or water seal drainage.

\section{Chest drains and closed underwater systems}

- If simple aspiration of any pneumothorax is unsuccessful in controlling symptoms, an intercostal tube should be inserted. Intercostal tube drainage is recommended in secondary pneumothorax except in patients who are not breathless and have a very small ( $<1 \mathrm{~cm}$ or apical) pneumothorax.

- Clean the area of affected chest where we are going to place intercostals drainage tube (ICDT). Site at 4th intercostals space in anterior axillary line towards upward direction for removal of air, towards downward direction for removal of fluid. Do small incision in the site where already decided to place ICDT Place the trocar and canula just above the upper border of the lower rib to avoid injury to intercostal vein, artery and nerve. With minimal force pierce the trocar $(2 \mathrm{~cm}$ in preterm, $3 \mathrm{~cm}$ in term baby) into the chest cavity to avoid injury to lung and to avoid placing ICDT too deep. Connect to under water seal, suture the site with silk and secure the ICDT/ dressing is must with plaster holding the ICDT tube.

- After air column is stopped moving or water column oscillation stopped oscillating clamp the ICDT, wait and watch for cyanosis or $\mathrm{SpO}_{2}$ dropping. If dropping of $\mathrm{SpO}_{2}$ seen or cyanosis noted. Remove the clamp, otherwise wait for 24 hours take chest x-ray if no air is accumulated remove ICDT, close the insertion site with gauze and immediately suture the wound to prevent air entering the pleural cavity from outside. If wound dressing is not done properly that might be the source of infection.

- Complications of chest tube drainage:

- Infection

- Bleeding

- Nerve damage

- Trauma

- Diaphragmatic paralysis

- Subcutaneous emphysema

\section{Prognosis}

Pneumothorax is a life-threatening condition with high mortality and morbidity. More common in neonate with birth weight less than 1500 $\mathrm{gm}$. and though incidence is less term neonate, may occur in spontaneously or with meconium aspiration syndrome.12 Air leaks are associated with an increased risk of intra-ventricular hemorrhage. ${ }^{13}$ There was a 13 fold increase in the composite outcome of death or broncho-pulmonary dysplasia if a pneumothorax occurs in first 24 hours of life of preterm baby. ${ }^{14}$

\section{Conclusion}

Pneumothorax can be suspected in a newborn baby if there is no improvement within a short period of resuscitation, if there is asymmetric chest movement during resuscitation. If there is sudden deterioration of a neonate on mechanical ventilation. Prompt diagnosis by urgent portable X-ray and immediate intervention is needed for life saving and better outcome. 


\section{References}

1. Al Tawil K, Abu-Ekteish FM, Tamimi 0 et al (2004) Symptomatic spontaneous pneumothorax in term newborn infants. Pediatr Pulmonol 37:443-446

2. Chernick V, Avery ME (1963) Spontaneous alveolar rupture at birth. Pediatrics 32:816-824.

3. May A.K. Abdel Latif, Dalia A.K et al. pneumothoraxin neonatal intensive care unit in Cairo University Hospital. J Egypt. Soc. Parasitol. . 42(2), 2012: 495-506.

4. Litmanovitz I, Carlo W A, Expected management of pneumothoraxin ventilated neonates. Pediatrics 2008; 122: e 975- e979.

5. Ogino MT. Pulmonary air leak , Manual of neonatal care, $5^{\text {th }}$ edn. Lippincott, Williams and Wilkins, 2004; pp 371- 377.

6. Hill A Perlman: Relationship of pneumothorax to occurance of intraventricular hemorrhage in premature newborn. Pediatrics 1982; 69:144-149.

7. Cloherty JP, Eichenwald EC, Stark AR. Pulmonary air leak. Manual of Neonatal Care $6^{\text {th }}$ edn;2008; 352- 357.

8. Goldsmith JP, Karetkin EH.Pulmonary air leak. Assisted Ventilation of the Neonate $4^{\text {th }}$ edn;2003;192-193.

9. Gomella TL. Pulmonary Diseases. Lange clinical manual Neonatology $5^{\text {th }}$ edn;2007 ; 524-530.

10. Northfield TC. Oxygen therapy for spontaneous pneumothorax. $\mathrm{Br}$ Med J 1971;4:86-8.

11. Stabilization and Transport of Newborn Infants and At-Risk Pregnancies. Editors ED Bowman, SM Levi, FE Presbury, A McLean. Newborn Emergency Transport Service, $4^{\text {th }}$ Edition, 1998.

12. May AK LA, Dalia AKAL. Pneumothorax in neonatal intensive care unit in Cairo University Hospital. Journal of Egyptian Society of parasitology, 42(2); 2012: 495-506.

13. Verma RP, Chandra S, Niwas R, Komaroff E. Risk factors and clinical outcome of pulmonary interstitial emphysema in extremely low birth weight infants. J Perinatol 2006;36: 197.

14. Power WF, Clemens JD. Prognostic implications of age at detection of air leak in very low birth weight infants requiring ventilator support. J Pediatr 1993; 123: $611-7$ 